\title{
MODERNIZATION OF THE DEVELOPMENT OF CITIES IN BULGARIA THROUGH THE INTRODUCTION OF INFORMATION TECHNOLOGY
}

\author{
Assoc. Prof. Dr. Kamen Petrov \\ UNWE, Bulgaria \\ petrovkamen@abv.bg \\ DOI: 10.47760/cognizance.2021.v01i10.001
}

\begin{abstract}
This article presents trends in the development of sustainable urbanism, in which innovations and technologies are brought to the fore. It is assumed that at this stage the necessary measures are being introduced to improve the efficiency of services and the use of resources in smaller machines (energy efficiency or efficiency in your enterprises) with information technology. This creates the conditions within the regional development offer to develop a concept of a smart city ("smart city"). In practice, the smart city is growing beyond this initial goal to one that applies to entire cities and urban blocks, not just the transport system or buildings, and covers a large area. This raises the need to study the development of settlements in order to better illustrate the processes of development of geo-spaces through the prism of the introduction of new communication technologies.
\end{abstract}

Keywords: urbanization, area, space, information, technologies, development, environment and management

\section{Introduction}

This exhibition aims to focus its focus on urban development and proposes that cities be seen as platforms for integrating policies aimed at achieving sustainability, both between different sectors and between different levels of cooperation, from local to international. Informed decision-making in crises such as the COVID-19 pandemic requires comprehensive, up-todate, timely and easily accessible information, reliable data and indicators and their proper assessment. In order to solve this problem and ensure the timely adoption of the necessary measures to protect the most vulnerable groups, it is necessary to develop appropriate monitoring programs, information management systems and evaluation procedures and solutions. On the other hand, the introduction of new technologies creates confidence that the future development of large cities cannot be achieved without the introduction of working information technologies. The territorial component is important in the current development of cities. Due to the continuing territorial (geographical specificity) inequality, including a coordinated approach at many levels and stakeholders for sustainable urban development is needed. This new approach to the introduction of information and communication technologies increases the level of services provided and at the same time makes cities more comfortable to live. Thus, the well-being and prosperity of each city become increasingly dependent on technological innovations. In this regard, we can assume that no nation can claim sustainability if many of its cities are not at the required technological level and pace of development. For example, in the last year the introduction of 5G technologies has become especially relevant, which in practice means the fifth generation in mobile communications. Unlike its predecessors, however, in the new technology, the connections and data exchange between devices, antennas and servers are much closer and more comprehensive. In this way, it becomes possible to connect many more appliances, which will facilitate technologies 


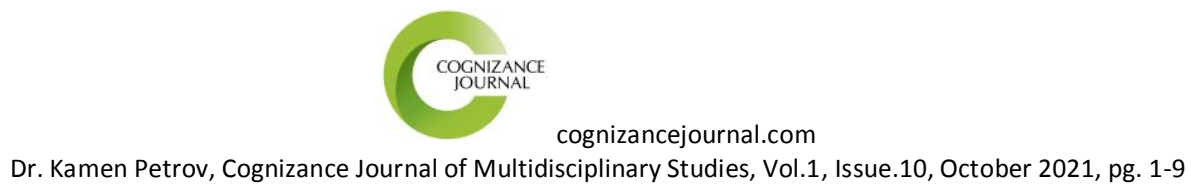

ISSN: 0976-7797

related to urban management, their use in the household, autonomous driving, innovation in industrial production and the speed of the Internet. Response time to the transmission of information is important for everything that is done in real time - from online gaming through a mobile device, virtual reality-based services, to medicine and autonomous vehicle movement. The change will allow the imposition of a standard with negligible delay in any action requiring precision. The doctor will be able to remotely control a device that performs real-time diagnostics, or even perform surgery. An operator will be able to remotely control vehicles, measure the values of electronic water meters, as well as make deliveries to the respective homes. We can assume that digital technologies are increasingly integrated into urban design and management. Implementing them, urban governance, infrastructure and finding smart solutions to support the integration and coordination of urban conditions will promote the possibility of providing citizen-oriented services. Although these technologies are not a panacea and need to be adapted to the real needs of cities, they are able to provide efficiency gains and rationalization. Urban operating systems implemented together with digital twins are called to create comprehensive and optimized ways of managing municipal services and transport infrastructure. Cities are experimenting with robotics and autonomous systems (e.g. connected self-driving cars, health robotics, building automation for energy efficiency). This means that if we want to have a modern regional development, we must look for solutions at the regional level and with the introduction of new technologies in urban management and local business development. New internet sharing platforms also open up opportunities that were previously underused and creating new markets (e.g. sharing cars, bikes, houses). Cities are increasingly aware of the ethical and social challenges that have arisen in the process of transition to digital technologies. Socially smart cities strive to be digitally inclusive, empowering and providing value and benefit to all citizens. Another important issue for the development of urban spaces is their mapping (1). Mapping is an important element of broadband planning and provides a basis for EU evaluation for all its members. Broadband mapping helps to target funding more efficiently and facilitates planning. On the other hand, unsatisfactory mapping can lead to insufficient financial viability of both public and private investments. Broadband mapping is the collection and presentation of data related to broadband deployment. This mapping is not just about geo-reference visualization; it covers the whole process of data collection. This can be data on the deployment of the broadband infrastructure itself, i.e. copper or optical cables, and may be connected to infrastructure such as ducts and pipes. In addition, the mapping of broadband must take into account the real supply and demand for broadband services, as well as existing and planned investments in broadband infrastructure.

\section{Innovative development and functioning of urban systems}

Urbanization is defined as a new central force in the overall development of civilization in the new urban program adopted by Habitat III in 2016. It is a landmark document that sets a global vision for urban development over the next two decades. In developing a New Urban Development Agenda for a number of important directions, including through the main recommendations for sustainable housing and urban development (2). At the heart of cities' enormous potential for sustainable development are people as communities and as individuals living today and those who will live tomorrow. Society is certainly responsible for many of the problems facing our planet. However, the innovation and transformation potential of cities 


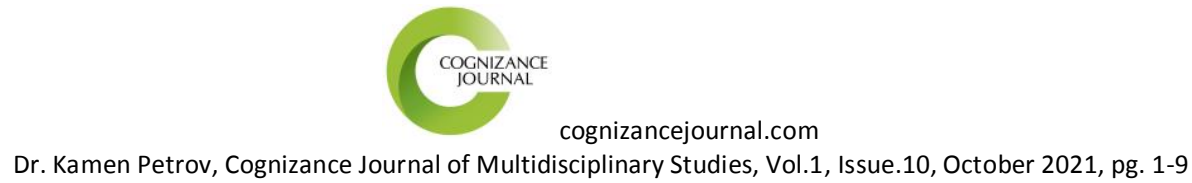

ISSN: 0976-7797

should not be taken for granted. This function of cities needs to be clearly recognized and promoted at all levels of government and that the necessary powers are given at these different levels. The creation of favorable conditions for innovation is associated with a number of factors, all of which must be present in order to create a living ecosystem and a reliable information environment. Cities that strive to create a better and more sustainable environment provide an integrated combination of housing, urban and social infrastructure. These sectors are part of the functioning of the 'urban economy', which is becoming an increasingly distinct advantage in urban life, which is crucial for the creation of a new urban consumer culture and business in cities. This aspect of the development of urban systems in the XXI century sets a new fragmentation of the models of regional development. The prism of innovation is increasingly intertwined with spatial development, but on the other hand, these processes also have their workload and oversaturation. This defines innovation as an introduction to the use of any new or significantly improved product (product or service) or process, a new marketing method or a new organizational method in business practice, the organization of workers places or external relations (1). Innovation encompasses the creation and application of new knowledge that redefines the path to a more sustainable future. In addition to new technologies or new products, innovations may include new management methods and organizational methods, new ways of structuring partnership relationships, or new ways of managing social relationships. In other words, the concept of innovation goes far beyond research, high-tech start-ups and even business-oriented to profit from private sector activities. It's about trying and defining better ways to improve communication and well-being. This process is part of creating a more attractive urban environment for all social groups and ages. For example, in the context of aging, cities support the environment for a healthy lifestyle and well-being and create the conditions for older people to "grow old on the spot" in a pleasant environment. In such cities housing, social transport infrastructure meets the needs of the elderly and people with disabilities. Another important issue is energy efficiency, which can also find better management through information technology. Almost everywhere there is a tendency to tighten energy efficiency standards for new buildings and residential buildings and to ensure energy recovery in existing buildings, as well as the exchange of experience between cities. Cities are shifting energy supplies to cleaner energy sources and modernizing energy infrastructure. It is very possible to achieve by focusing on transport, which is still used mainly by fossil fuels. It is very possible for the local economy and public administration to focus municipal procurement on clean energy and green technologies for public services. Such an important priority is to reduce pollution from transport, which is an effective lever for a green transition along with urban planning and to stimulate the transition from mobility to greener regimes. In order to find new and innovative solutions, experimentation and the search for new things are important. Smart policy measures are an ongoing search process, not a prescribed set of strategies with expected results (12). To make full use of their innovation potential, cities are developing an open culture of flexible governance that promotes reflective learning, adaptation, creativity, innovation, co-creation and the maintenance of innovative business models (3). This includes experimental multi-level governance mechanisms to facilitate collaboration between different sectors to gain experience and knowledge of what works, gain confidence and develop, test, adjust and scale ideas. 


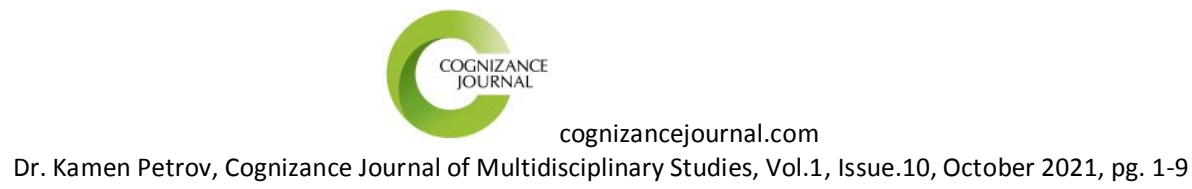

ISSN: 0976-7797

\section{Innovation is the key to sustainable urban transformation}

Cities bring together industries, entrepreneurs, research and educational institutions, people capital, efficient infrastructure, a wide variety of consumer demand and preferences, Investors responsible and responsive to the needs of citizens Politicians and officials person, culture and, importantly, different types of talent. Leading cities have a critical appraisal system that allows you to define the main problems or what works and what doesn't! This creates an environment that provides opportunities for change and, above all, to eliminate what does not work, avoiding maintaining the "status quo" and situations in which the choice of one option complicates the choice of a more successful option in the future (4). A principled approach to the development of sustainable practices must be based on real results and awareness, allows understanding and evaluation of decisions in practice. In order to take the innovative approach as a leader, it should be borne in mind that the concentration of all elements in one location serves as a fertile ground for innovative ideas to create opportunities and ultimately to address the challenges of sustainable development that currently face the world, including congestion, energy and resource depletion, environmental pollution, public health, waste management and housing affordability. In order to take the innovative approach as a leader, it should be borne in mind that the concentration of all elements in one location serves as a fertile ground for innovative ideas to create opportunities and ultimately to address the challenges of sustainable development that currently face the world, including congestion, energy and resource depletion, environmental pollution, public health, waste management and housing affordability. These include in themselves the application of approaches developed under other conditions. It is important to note that innovation in this context includes not only technologies but also mechanisms for applying knowledge, ideas, practices and new and better ways to address today's dilemmas and challenges (5). This is in line with the established model of building "sustainable cities" as one of the main directions of urban development since the early 90's of the twentieth century for sustainable development, which has become a social paradigm. The development of urban systems is often defined as a political commitment. The concept of a sustainable city is imposed, which is considered a city that finds a balance between social, economic and environmental problems and processes in the spatial aspect. Sustainable cities are often associated with a number of relevant regulatory visions for urban development. For example, cities must be economically rich at the same time (productive cities, competitive cities, creative cities), socially responsible (open cities, comfortable cities to live in, fair cities, comfortable for the elderly) and ecologically literate (resource-saving cities, green eco-cities), sustainable cities). Rapid trends of urbanization are transformed into a growing and urgent demand for new or improved infrastructure, services and institutions capable of solving the triune task: 1) ensuring access of the growing urban population to basic services and vital resources; 2) maintaining continuous economic growth and 3) managing resources within the limitations of our planet in solving the problems of adaptation to climate change and mitigating its consequences. Cities are already major socioeconomic assets and are a driving force for development in all countries (including those where the population still lives mainly outside the cities). This is largely due to economic and cultural globalization. Driving factors of globalization are advances in telecommunications, digital technologies, transport systems and trade liberalization (6). At the same time, globalization requires an increase in the pace of socio-economic development interactions, 


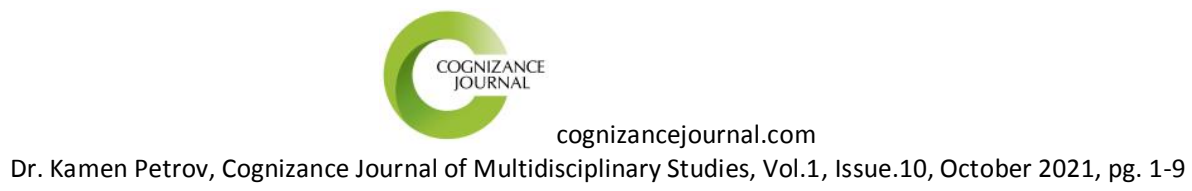

ISSN: 0976-7797

forcing people to move to cities, especially large cities, with their advantages proximity, accessibility and exceptional productivity. It determines the productivity of cities agglomeration effect, economies of scale, knowledge sharing, business interaction, access to jobs, finance, entertainment, media, art and other services. Competitive and attractive cities stimulate job growth, income growth and labor productivity, even if there are huge differences between cities and regions in terms of performance. In this way, geo-urbanization restructures geography both globally and locally, strengthening the urban hierarchy, with large metropolitan areas enjoying a special privilege as centers of globalization, although all cities in the structure of the urban hierarchy play their role within the architecture of the new economic geography. The role of cities in promoting social development must be seen in the context of the wider trends and challenges of social development to which all cities must adapt in one way or another.

These trends and challenges also open new opportunities, lead to the formation of new functions of cities in society. Relative economic performance, employment opportunities and wages are some of the indicators that often show differences between cities (7). These differences often cause a chain reaction. For example, a steady decline in the city's economic performance and lack of economic opportunities lead to a brain drain, loss of skilled staff and relocation of jobs to other more prosperous communities. This reduces the ability of the public and private sector to ensure the sustainability of the budget of such a settlement, as well as the provision of services and maintenance of infrastructure. As a result, the level of business development decreases and innovation. Over time, qualitative and quantitative differentiation between settlements is only intensified, which leads to uneven quality of life. As central places systematically gain advantages (economic, cultural and / or political) over peripheral areas, this can be seen as a spatial or territorial injustice, contrary to the idea of sustainability. Related to this is the phenomenon of urban shrinkage. These are the cities that are experiencing a decline in population (13). This process is relative, the decrease is of different intensity in different cities and runs in parallel with the growth in other cities, which attract population. At the same time, these processes after 2019 were placed on a new plane. The rapid growth of the use of digital technologies, including digital communications and infrastructure and other advanced technologies, has changed many areas of public life, including production and consumption, how people interact with each other and how people work and behave. Isolation measures in response to the COVID-19 pandemic and the temporary shift to teleworking also demonstrate the prevalence of digital transformation in society. This change has led to the elimination of the link between the workplace and the place of residence has suddenly become the norm for many more people, even those who do not normally do work away from the traditional workplace. This showed that the world is moving towards a new technological change.

\section{Development of the city's economy through information technologies and networks}

Cities contain colossal resources, human talents, creativity and serve as centers for sharing knowledge, experimentation and innovation, generating new ideas and implementing these solutions at the local level, the most successful of which is scaled up in a wider application. However, cities are not abstract machines for sustainable development; real people live, work, study and realize themselves in cities. Cities consist of people built by people and existing for 


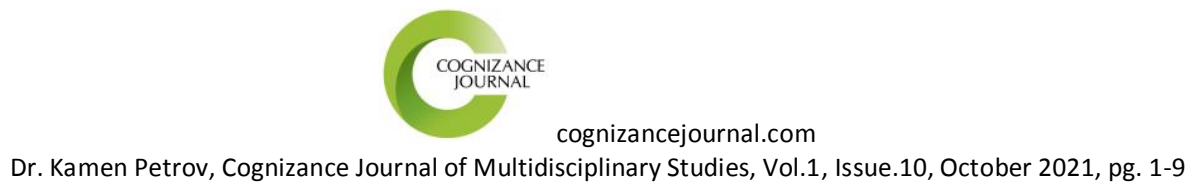

ISSN: 0976-7797

people. Therefore, sustainable development measures must make sense above all for the city dwellers themselves, making their lives more comfortable. Moreover, people are the driving force behind sustainability, its source and beneficiary. This vision is at the heart of the concept of "people-smart sustainable cities". By promoting sustainability in all its environmental, economic, social and cultural dimensions, such cities create the conditions and infrastructure to empower their citizens to contribute to and benefit from a better, more sustainable and sustainable development city (8). Such cities form an environment for the full participation of citizens in the exercise of their rights. to the town. The focus is on making cities more prosperous, fair, comfortable and innovative, meeting social needs and ensuring high quality and affordability of housing and urban services. These cities meet the needs of vulnerable groups and people with disabilities, gender and age, recognizing the needs of residents are different and change at different stages of life. This approach is comprehensive and equitable, directly and clearly linking sustainable development to human capital development, and also reaffirming the urgent need to expand life opportunities and improve the quality of life for all.

Citizens are seen as a source and as beneficiaries of sustainable development. These ideas are based on the concepts of "sustainable cities" and "smart cities" (9). stakeholders to participate in joint, inclusive and at the same time pragmatic policies for sustainable development. The continuing digitalization and the development of intelligent technologies have influenced the conceptualization of sustainable cities, the introduction of the intelligent dimension as a new normative requirement for a technological society. But the concept of "smart city" has changed over time: there is a change from the concept that some are now called "Smart City 1.0" (which features a top-down system, with a focus on ICT infrastructure and the implementation of solutions driven by technology companies), to the concept of "Smart City 2.0" (a system that is focused on people and user-friendly) and even Smart City 3.0 (inclusive governance and participatory urban management). In terms of technology, instead of blindly copying and applying what other cities do, there is a search for "really smart" solutions for cities that are tailored to the needs of specific cities and their inhabitants, taking into account their characteristics, aspirations and challenges. (10). This approach is more in line with the concept of adaptive control. Intelligence is certainly one of the conditions for more sustainable development, but at the core of this concepts must be people, citizens, communities. In this publication, the concept of "socially smart sustainable cities" refers to an extremely "humanistic" vision of a "smart" city, which includes, but is not limited to, ICT or technology, but extends far beyond them. for a socially intelligent sustainable city promotes a broader understanding of intelligence in urban development - as a set of conditions aimed at strengthening human capital, while ensuring sustainability and creating a harmonious society and improving the quality of life. This means meeting social needs and creating more favorable conditions in cities for innovation, which will make cities more attractive to people and businesses (11). This approach sets the new trend, which focuses on creating an enabling environment that makes cities socially smart and opens the door to a more sustainable and comfortable future. It also demonstrates that cities are key forces for introducing and implementing innovation for a sustainable future. In practice, this environment cannot go through the implementation of new communication technologies such as 5G. In addition to the basic terminology and important trends, at the level of cities and in particular in Bulgaria as municipalities, efforts will have to be made for the introduction of 5G technology. There are already working $5 \mathrm{G}$ networks in Bulgaria, although in test mode. The reason this is not really felt is that these are working networks, but with many reservations: limited coverage, limited speed and most of all a limited number of devices that can be included in it. In 


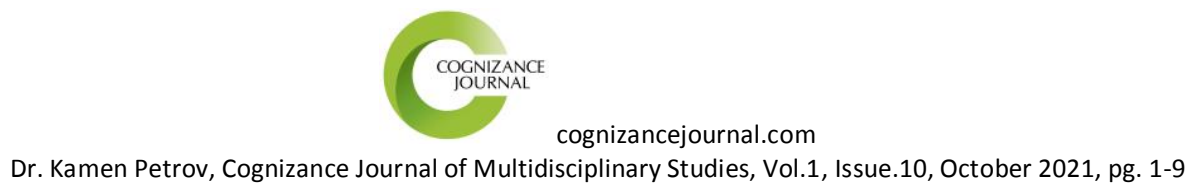

ISSN: 0976-7797

addition, even if the construction of a $5 \mathrm{G}$ network can be completed in the next few years, it will be unusable - there will not be enough mobile devices adapted to work with it. The successful and timely introduction of $5 \mathrm{G}$ networks will require a significant change in infrastructure investments, which will require significant coordination and development of regulatory frameworks. $5 \mathrm{G}$ mobile networks will be vital to sustaining the growing demand for mobile video. Increased data transfer capacity, speed and low latency will allow ordinary users to have fun through so-called virtual reality (VR) and alternate reality (AR). These technologies are already helping to enhance the experience in sports and other live events with innovations such as AR games and interactive gaming programs, while VR is helping to recreate a live experience for those at home and on mobile devices. Currently, virtual reality bandwidth is almost 100 times higher than playing high-definition video. 5G will allow for more innovation in this area. Given the complexity of future 5G systems, it is not yet clear how and where 5G networks will be located. It is possible that their development will be part of a much broader wireless ecosystem, based on investment in $4 \mathrm{G}$ networks and the improvements needed to provide different uses in different areas. Connecting hotspots is likely to provide additional capacity for hundreds of thousands of small short-range and highspeed cellular radios that support the existing network. Thus, 5G will require a gradual change in investment in digital communications infrastructure, as well as the necessary skills to provide its capabilities. Applications transform the user experience with urban spaces and services, including how people receive information, communicate, interact with each other, move, access places and participate in public and political life. Many other features for urban living applications include the following in themselves:

Urban mobility. Smartphone applications use a built-in navigation feature to adapt to different modes of transport. Many public transport services provide real-time traffic schedules, traffic information, the ability to purchase tickets online and track access to bus or train stops from geolocation.

Car sharing. These applications offer access to car sharing services, allowing the user to find free cars and rent them on an hourly basis or to access the car sharing services of several colleagues on joint trips. Taxi calling services make it easy to order a taxi, search for it in real time and pay for the trip online through the app. This is exactly what 15 toGO does - it connects people with common interests and desires to visit a certain destination. When users use the Travel with Me button, they offer a "travel friendship" using the term travelship in the platform. The more people accept the invitations, the greater the network of travelers created by the respective user.

Shopping and delivery. Retail and supermarket chains provide applications that provide access to their products, allow you to place a purchase order, and help you find nearby stores. You can also order food and its delivery by accessing the menu of restaurants and independent delivery services.

Financial services. This group includes applications for daily use of mobile devices bank and online payment by phone in stores or when receiving services, which replaces a credit or debit card. Such applications also allow those who do not have a card payment machine to make small personal money transfers (12).

Short-term rent. Find hotel rooms, compare prices, book a room and manage the reservation can be made both from a smartphone and a desktop computer. With the growth of the sharing economy. These possibilities are not limited to hotel rooms, but also cover services for sharing (short-term rent) of residential premises.

E-government or e-government. Receiving government services directly through smartphones is becoming commonplace. Many local authorities provide applications to make 


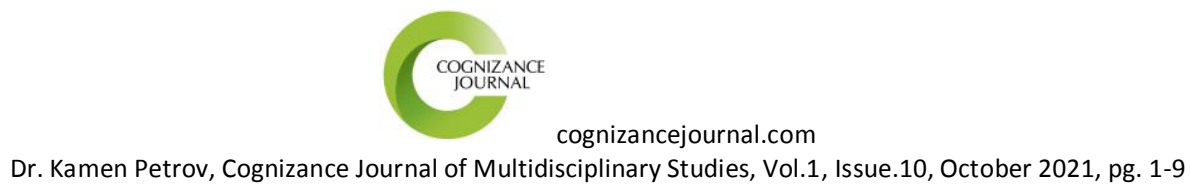

ISSN: 0976-7797

it easier for citizens to inform the authorities and participate in the decision-making process. These include reported infrastructure gaps using geographically indicated images and brief descriptions that are sent to the relevant services.

Medical care. The applications also change the way we approach healthcare, some of the applications proved useful during the COVID-19 epidemic.

The digital revolution provides cities and citizens with new tools to find opportunities, solve problems and create pathways to a more sustainable and comfortable future for all. This is particularly true of the fourth industrial revolution (Industry 4.0), automation and robotics, which can change the way businesses work, the organization of social life and its impact on labor markets (13).

Finally, we cannot ignore the fact that the information society is a stage of the development of civilization, let's assume that the new technologies lead to a qualitatively new structure, organization of public relations based on global access and use of information, communication networks and services. Through information technology it is possible to overcome national, geographical or other restrictions on the exchange of information on scientific, spiritual, cultural and other achievements.

\section{Conclusion}

It is a determining factor in public life as a whole scientific knowledge. It displaces labor (manual and mechanized) as a factor in the value of goods and services. The economic and social functions of capital pass to information. Thus, the urbanism of the platform and smart cities are some of the trends in the commitment of cities in the digital transition. They recognize cities as suitable metropolitan areas for the introduction of "smart" technologies, including in an experimental, "test" mode. Various "Platforms" introduce new services and markets in urban life, enabling more efficient and cost-effective, opening up new opportunities for service providers and offering more convenient and cost-effective services. The sharing economy involves activities based on user-user interaction, which allows transactions between buyers and sellers, usually supported by Internet platforms. The model allows the creation of new markets in which consumers can profit from underused or unused assets, such as cars or real estate. Airbnb, Uber and their regional alternatives such as Yandex.Taxi and other Yandex services and other similar platforms quickly became part of everyday life. Car-sharing services by several other passengers, such as Oszkár in Central Europe, car-sharing and bicycle-sharing platforms are widespread (3). Similarly, collaboration platforms and freelance practice help to better balance supply and demand in a more flexible labor market. The platforms are evolving due to network effects and economies of scale. This predetermines the entry of $5 \mathrm{G}$ technologies within the Bulgarian national space. The infrastructure of the information society is the new intelligent, not the mechanical technology. The social organization and information technologies form a kind of symbiosis. Society enters an technotronic era when social processes become programmable. There is a lot of information in modern society as well plays a colossal role. To understand the essence of the information and why it plays such an important role in the modern age is needed clearly distinguish message (or message), interpretation perception) and communication. Modernization goes through the introduction of new technologies and their management in order to create a new labor market that brings to the fore new professions and winds of the economy of the XXI century. 


\section{References}

[1]. Bulkeley, H. et al. (2016). "Urban living labs: governing urban sustainability transitions". Current Opinion in Environmental Sustainability. 22:13-17. DOI: https://doi.org/10.1016/j.cosust.2017.02.003.

[2]. Habitat III (2016). New Urban Agenda. https://unhabitat.org/sites/default/files/2019/05/nuaenglish.pdf.

[3]. Carbon Neutral Cities Alliance (2019). Carbon Neutral Cities Alliance 2019 Annual Report. https://carbonneutralcities.org/cities/.

[4]. Golubchikov, O. and K. O'Sullivan (2020). "Energy periphery: Uneven development and the precarious geographiesof low-carbon transition". Energy and Buildings. 211. DOI: https://doi.org/10.1016/ j.enbuild.2020.109818.

[5]. EASME and DG GROW (2019a). Digital Cities Challenges: Designing Digital Transformation Strategies for EU Cities in the 21st Century. Luxembourg: Publications Office of the European Union. https://www.digitallytransformyourregion.eu/sites/default/files/2019-09/EA-04-19-484-EN-N.pdf.

[6]. EASME and DG GROW (2019b). Digital Cities Challenges: Designing Digital Transformation Strategies for EU Cities in the 21st Century. Final Report. Luxembourg: Publications Office of the European Union. https://www.intelligentcitieschallenge.eu/sites/default/files/2019-09/EA-04-19-483-EN-N.pdf.

[7]. Friedman, K., C. Conteh and C. Philips (2019). "Cross-border innovation corridors: How to support, strengthen and sustain cross-border innovation ecosystems". Niagara Community Observatory, Brock University.https://brocku.ca/niagara-community-observatory/wp-content/uploads/sites/117/NCO-Policy-Brief-42Friedman-Cross-Border-Innovation-FINAL.pdf.

[8]. Klinenberg, E. (2018) Palaces for the people: How social infrastructure can help fight inequality, polarization, and the decline of civic life. London: Penguin.

[9]. Latham, A. and J Layton (2019). "Social infrastructure and the public life of cities: Studying urban sociality andpublic spaces". Geography Compass. e12444. DOI: https://doi.org/10.1111/gec3.12444.

[10].Nesti, G. (2019). "Mainstreaming gender equality in smart cities: Theoretical, methodological and empirical challenges". Governing Smart Cities, 24 (3): 289-304. DOI: https://doi.org/10.3233/IP-190134.

[11]. Valkov Vladimir The impact of pensions for insurance experience and age on the social insurance system yearbook of UNWE 2020 (2); ISSN (online): 2534-8949

[12].Rutherford, J. and O. Coutard (2014). "Urban Energy Transitions: Places, Processus and Politics of Socio-technical Change". Urban Studies 51(7):1353-1377. DOI: https://doi.org/10.1080/19406940.2016.1272620.

[13]. Yenneti, K., R. Day and O. Golubchikov (2016). "Spatial justice and the land politics of renewables: Dispossessing vulnerable communities through solar energy mega-projects". Geoforum 76:90-99. DOI: https://doi.org/10.1016/j.geoforum.2016.09.004. 